\title{
Fermentação ruminal e produção de metano in vitro de dietas contendo torta de algodão
}

\section{In vitro rumen fermentation and methane production from diets containing cottonseed cake}

\author{
André Luiz Custódio Franco ${ }^{1 *}$; Ivone Yurika Mizubuti²; \\ José Augusto Gomes Azevêdo³; Edson Luís de Azambuja Ribeiro²; \\ Elzânia Sales Pereira"; Eduardo Lucas Terra Peixoto'; \\ Diêgo Mendes Freitas Ferreira ${ }^{6}$; Adony Querubino de Andrade Neto ${ }^{6}$
}

\section{Resumo}

Objetivou-se avaliar o efeito da substituição da proteína do farelo de soja pela proteína da torta de algodão em dietas de bovinos de corte sobre suas frações de carboidratos e proteína, cinética de fermentação ruminal e produção de metano in vitro. A torta de algodão substituiu 0,$0 ; 0,25 ; 0,5 ; 0,75$ e $1 \mathrm{~kg} \mathrm{kg-1}$ PB da proteína do farelo de soja em dietas, todas com relação volumoso:concentrado de 60:40 e isonitrogenadas. Foi utilizada a técnica in vitro de produção cumulativa de gases. Os níveis de substituição reduziram a proporção de açúcares solúveis (Fração A + B1), e aumentaram a fibra potencialmente degradável (Fração B2) e indigestível (Fração C), sem alterar os carboidratos totais. O aumento nos níveis de substituição reduziram os compostos nitrogenados não protéicos (Fração A), enquanto incrementaram a proteína verdadeira rapidamente degradadável somada à fração de degradação intermediária (Fração B1+B2) e a proteína indigestível (Fração C) nas dietas experimentais. A taxa de degradação dos carboidratos fibrosos apresentou efeito quadrático negativo aos níveis de substituição, sendo que o volume final de gases produzido não foi influenciado. A cinética de degradação dos carboidratos não fibrosos não foi influenciada pela substituição da proteína do farelo de soja pela torta de algodão, assim como o tempo de colonização. Entre zero e 12 horas de incubação, as dietas influenciaram tanto a produção como a proporção de metano com efeito quadrático negativo. Os maiores tempos de incubação, entre 12 e 24 horas, produziram em média $73 \%$ da quantidade total de metano, sem apresentar efeito dos tratamentos. Não houve diferença na produção total de metano na MS incubada e na quantidade de energia digestível entre as dietas. A substituição do farelo de soja pela torta de algodão como concentrado protéico em dietas não influencia a produção de metano em 24 horas de fermentação.

Palavras-chave: Alimentos alternativos, bioenergia, biodiesel, gases de efeito estufa, ruminantes

\footnotetext{
${ }^{1}$ M.e. em Bioenergia, Discente de Doutorado em Solos e Nutrição de Plantas, Escola Superior de Agricultura Luiz de Queiroz, ESALQ. Piracicaba, SP. E-mail: andrefranco agro@hotmail.com

${ }^{2}$ Profs. Drs. do Dept ${ }^{\circ}$ de Zootecnia, Centro de Ciências Agrárias, Universidade Estadual de Londrina, UEL, Londrina, PR. Bolsistas de Produtividade do CNPq.E-mail: mizubuti@uel.br; elar@uel.br

${ }^{3}$ Prof. do Dept $^{\circ}$ de Ciências Agrária e Ambientais, Universidade Estadual de Santa Cruz, UESC, Ilhéus, BA. Bolsista de Produtividade do CNPq. E-mail: augustog@uesc.br

${ }^{4}$ Prof $^{\mathrm{a}} \mathrm{Dr}^{\mathrm{a}}$ do Dept ${ }^{\mathrm{o}}$ de Zootecnia, Centro de Ciências Agrárias, Universidade Federal de Fortaleza, CCA/UFC, Fortaleza, CE. Bolsista de Produtividade do CNPq. E-mail: elzania@hotmail.com

${ }^{5}$ Discente de Doutorado do Programa de Pós-graduação em Ciência Animal, UEL. Londrina, PR. E-mail: eduzootec@hotmail.com

${ }^{6}$ Discente(s) de Graduação do curso de Medicina Veterinária, UESC, Ilhéus, BA. E-mail: diegomendes.medvet@hotmail.com; adony_neto@yahoo.com

* Autor para correspondência
} 


\begin{abstract}
This study evaluated the effect of replacement of soybean meal protein by protein from cottonseed cake in diets for beef cattle on their carbohydrate and protein fractions, in vitro rumen fermentation kinetics and methane production. The cottonseed cake protein replaced 0,$0 ; 0,25 ; 0,5 ; 0,75$ and $1 \mathrm{~kg} \mathrm{~kg}-1 \mathrm{CP}$ of soybean meal protein in diets with forage:concentrate ratio of 60:40. In vitro gas production technique was used. Variations in the composition of carbohydrates and protein fractions from formulated diets supported the discussion of results of the rumen fermentation and methane production. Although fibrous carbohydrates degradation rate has presented a quadratic effect to treatment, the final gas volume produced by its degradation was not affected. Non-fiber carbohydrates degradation kinetics was not influenced by replacement of soybean meal protein by cottonseed cake protein, since their degradation rates and final gas volume had no significant effect on treatments, as well as, the lag time. Between zero and 12 hours of incubation the treatments affected both, production and proportion of methane, with a negative quadratic effect. The highest incubation times, between 12 and 24 hours, produced on average $73 \%$ of the amount of total methane, without effect of treatments. As a result of methanogenesis observed for all diets after 12 hours of incubation, there was no difference in total methane production in the DM incubated and amount of digestible energy (DE) between treatments, in other words, there was no mitigation or increase in methanogenesis by any inclusion level of cottonseed cake compared to the control treatment. Meat or milk come from animal production systems using co-products of biodiesel produced from oleaginous seeds, such as, soybean and cotton have similar environmental performance as enteric methane emissions.
\end{abstract}

Key words: Alternative foods, bioenergy, biodiesel, greenhouse gases, ruminants

\section{Introdução}

O setor agropecuário é o principal emissor de $\mathrm{CH}_{4}$ e $\mathrm{N}_{2} \mathrm{O}$ para a atmosfera (WHEELER; LEDGARD; DE KLEIN, 2008), gases com potencial de aquecimento global, respectivamente, 23 e 298 vezes maior que o $\mathrm{CO}_{2}$ (RAMASWANY et al., 2001; SOLOMON et al., 2007). Particularmente a fermentação entérica em animais ruminantes (predominantemente bovinos e ovinos) produz, em escala global, entre 21 e $25 \%$ do total das emissões antropogênicas de metano (LASCANO; CÁRDENAS, 2010). De fato, o metano produzido no rúmen não só afeta a eficiência de utilização de energia pelos animais, mas também contribui significativamente para a poluição ambiental. Assim, alimentos alternativos que por anos têm sido estudados com vistas a melhorar o desempenho dos animais e aumentar as margens da atividade, recentemente passaram a ser investigados também quanto ao potencial para redução nas emissões de metano entérico (HOPKINS; DEL PRADO, 2007; KEBREAB et al., 2010; LASCANO; CÁRDENAS, 2010).
O sucesso do Programa Nacional de Produção e Uso do Biodiesel (PNPB), lançado em 2004 concomitantemente com o marco regulatório que estabeleceu as condições legais para a introdução do biodiesel na matriz energética brasileira de combustíveis líquidos, tem contribuído com a atual expansão de $6,5 \%$ ao ano da capacidade instalada de processamento de grãos oleaginosos no país, registrada pela Associação Brasileira das Indútrias de Óleos Vegetais (ABIOVE). Analisando os dados dos boletins mensais do biodiesel e do relatório de produção nacional de biodiesel puro - B100, da Agência Nacional do Petróleo, Gás Natural e Biocombustíveis (ANP), observa-se que embora o óleo de soja componha $80 \%$ da matriz oleaginosa para produção de biodiesel, dos 1,712 bilhões de litros deste biocombustível produzidos no Brasil de janeiro a agosto de 2011, ao menos 3\%, ou seja, aproximadamente 51 milhões de litros utilizaram o óleo de algodão como matéria prima, sendo esta a terceira principal fonte de óleo (BRASIL, 2011), gerando como co-produto, à partir desta cadeia produtiva, cerca de 245 mil toneladas de torta residual de algodão. 
A substituição do farelo de soja pela torta ou farelo de algodão não influencia o desempenho de vacas de leite em confinamento (SILVA et al., 2009; ALVES et al., 2010) ou de novilhas de corte em pastejo recebendo suplementação protéica (BARROS et al., 2011). Silva et al. (2009) e Alves et al. (2010) relataram não haver efeito de níveis de farelo de algodão em substituição ao farelo de soja sobre a digestibilidade dos carboidratos não fibrosos em dietas de vacas leiteiras em produção. Abdalla et al. (2009), não encontraram efeito da substiuição do farelo de soja pelo farelo de algodão e tortas de dendê, mamona, nabo forrageiro e tremoço, em dietas com relação volumoso:concentrado 70:30 sobre a produção de metano após 24 horas de incubação in vitro.

A mensuração da produção de metano entérico por meio de técnicas de produção de gases in vitro tem refletido com acurácia os acontecimentos in vivo, sendo, portanto, adequadas para formação de uma base de dados de produção potencial de metano de diversas dietas para ruminantes e análise de estratégias para mitigar as emissões (GETACHEW et al., 2005; BHATTA et al., 2006).
A torta de algodão pode apresentar características desejáveis a um concentrado protéico de boa qualidade para alimentação de ruminantes e potencial de mitigação das emissões de metano na fermentação ruminal. Assim, avaliou-se os efeitos da substituição do farelo de soja pela torta de algodão como concentrado protéico em dietas sobre as frações de carboidratos e proteínas, cinética de fermentação ruminal e produção de metano in vitro.

\section{Material e Métodos}

Os alimentos constituintes das dietas foram analisados para determinação dos teores de matéria seca (MS), matéria orgânica (MO), proteína bruta (PB), extrato etéreo (EE), fibra em detergente neutro (FDN), fibra em detergente ácido (FDA), lignina (LIG), proteína insolúvel em detergente neutro (PIDN) e ácido (PIDA), conforme metodologias descritas por Mizubuti et al. (2009) (Tabela 1). A FDNcp corresponde à fibra em detergente neutro corrigida para os teores de cinza e proteína. Os cálculos para nutrientes digestíveis totais (NDT) e energia digestível (ED) foram realizados segundo recomendações do NRC (2001) (Tabela 2).

Tabela 1. Composição química dos alimentos componentes das dietas ( $\left.\mathrm{g} \mathrm{kg}^{-1} \mathrm{MS}\right)$.

\begin{tabular}{lcccc}
\hline Item & Silagem de Sorgo & Milho Moído & Farelo de Soja & Torta de Algodão \\
\hline Matéria Seca* & 307,2 & 907,7 & 890,1 & 916,6 \\
Matéria Orgânica & 951 & 988,5 & 945,8 & 948,7 \\
Proteína Bruta & 134,3 & 73,8 & 473,5 & 456,1 \\
PIDN & 7,8 & 2,7 & 24,2 & 10,4 \\
PIDA & 3,5 & 2,5 & 0,5 & 4,1 \\
Fibra em Detergente Neutro & 594,4 & 181,8 & 295 & 478,6 \\
FDNcp & 567,4 & 173,8 & 262,9 & 461,8 \\
Fibra em Detergente Ácido & 287,8 & 148,5 & 231,9 & 303,4 \\
Lignina & 31,1 & 2,4 & 6,4 & 49,5 \\
Extrato Etéreo & 14,8 & 32,2 & 10,3 & 10,4 \\
Carboidratos Totais & 802 & 882,5 & 462,1 & 482,1 \\
Carboidratos não fibrosos & 234,5 & 708,7 & 199,1 & 20,4 \\
\hline
\end{tabular}

Proteína insolúvel em detergente neutro (PIDN); Proteína insolúvel em detergente ácido (PIDA); Fibra em detergente neutro corrigida para cinzas e proteína (FDNcp).

* $\mathrm{g} \mathrm{kg}^{-1}$ matéria verde.

Fonte: Elaboração dos autores. 
Foram avaliadas cinco dietas, com relação volumoso:concentrado de 60:40, isonitrogenadas (141 $\mathrm{g} \mathrm{kg}^{-1}$ de proteína bruta (MS)), contendo 0,25 , 0,50, 0,75 e $1 \mathrm{~kg} \mathrm{~kg}^{-1} \mathrm{~PB}$ de torta de algodão em substituição à proteína do farelo de soja em relação a uma dieta controle, sem torta de algodão (Tabela 2).

As frações dos carboidratos foram obtidas utilizando-se a metodologia descrita por Sniffen et al. (1992), onde: Carboidratos totais, CHT ( $\mathrm{g} \mathrm{kg}^{-1}$ $\mathrm{MS})=100-\mathrm{PB}\left(\mathrm{g} \mathrm{kg}^{-1} \mathrm{MS}\right)-\mathrm{EE}\left(\mathrm{g} \mathrm{kg}^{-1} \mathrm{MS}\right)-\mathrm{MM}(\mathrm{g}$ $\left.\mathrm{kg}^{-1} \mathrm{MS}\right)$; Fração “C”" $\left(\mathrm{g} \mathrm{kg}^{-1} \mathrm{CHT}\right)=100$ * $(\mathrm{FDN}(\mathrm{g}$ $\left.\left.\mathrm{kg}^{-1} \mathrm{MS}\right) * 0,01 * \mathrm{LIG}\left(\mathrm{g} \mathrm{kg}^{-1} \mathrm{FDN}\right) * 2,4\right) / \mathrm{CHT}(\mathrm{g}$ $\left.\mathrm{kg}^{-1} \mathrm{MS}\right)$; Fração "B2" ( $\left.\mathrm{g} \mathrm{kg}^{-1} \mathrm{CHT}\right)=100$ * $(\mathrm{FDN}(\mathrm{g}$ $\left.\mathrm{kg}^{-1} \mathrm{MS}\right)-\mathrm{PIDN}\left(\mathrm{g} \mathrm{kg}^{-1} \mathrm{~PB}\right) * 0,01 * \mathrm{~PB}\left(\mathrm{~g} \mathrm{~kg}^{-1} \mathrm{MS}\right)$ $\left.-\mathrm{FDN}\left(\mathrm{g} \mathrm{kg}^{-1} \mathrm{MS}\right) * 0,01 * \mathrm{LIG}\left(\mathrm{g} \mathrm{kg}^{-1} \mathrm{FDN}\right) * 2,4\right)$ / CHT(g kg-1 MS); Fração "A+B1" ( $\left.\mathrm{g} \mathrm{kg}^{-1} \mathrm{CHT}\right)=$ $100-\left(\mathrm{B} 2\left(\mathrm{~g} \mathrm{~kg}^{-1} \mathrm{CHT}\right)+\mathrm{C}\left(\mathrm{g} \mathrm{kg}^{-1} \mathrm{CHT}\right)\right)$.

Tabela 2. Composição percentual dos ingredientes nas dietas e composição química das dietas $\left(\mathrm{g} \mathrm{kg}^{-1} \mathrm{MS}\right)$ de acordo com o nível de torta de algodão.

\begin{tabular}{|c|c|c|c|c|c|}
\hline \multirow{2}{*}{ Ingrediente } & \multirow{2}{*}{ Controle } & \multicolumn{4}{|c|}{ Nível de substituição $\left(\mathrm{kg} \mathrm{kg}^{-1} \mathrm{~PB}\right)$} \\
\hline & & 0,25 & $\mathbf{0 , 5}$ & 0,75 & 1 \\
\hline Silagem de Sorgo & 608,9 & 610 & 610 & 610 & 610 \\
\hline Milho Moído & 314 & 312,2 & 311,4 & 310,5 & 309,6 \\
\hline Farelo de Soja & 77,1 & 57,8 & 38,5 & 19,3 & - \\
\hline Torta de Algodão & - & 20 & 40,1 & 60,2 & 80,4 \\
\hline \multicolumn{6}{|c|}{ Composição das dietas } \\
\hline Matéria Seca* & 540,7 & 540,6 & 541,1 & 541,6 & 542,1 \\
\hline Matéria Orgânica & 962,4 & 962,4 & 962,4 & 962,4 & 962,4 \\
\hline Proteína Bruta & 141 & 141 & 141 & 141 & 141 \\
\hline Extrato Etéreo & 19,9 & 19,9 & 19,9 & 19,9 & 19,8 \\
\hline Fibra em Detergente Neutro & 441,8 & 446 & 449,7 & 453,5 & 457,3 \\
\hline FDNcp & 420,3 & 424,8 & 428,9 & 433 & 437 \\
\hline Fibra em Detergente Ácido & 239,7 & 241,4 & 242,9 & 244,4 & 245,9 \\
\hline PIDN & 7,5 & 7,2 & 7 & 6,7 & 6,4 \\
\hline PIDA & 2,9 & 3 & 3,1 & 3,2 & 3,2 \\
\hline Lignina & 20,2 & 21,1 & 21,9 & 22,8 & 23,7 \\
\hline Carboidratos Totais & 801 & 801,1 & 801,1 & 801,1 & 801,2 \\
\hline Carboidratos não fibrosos & 413,1 & 409,8 & 406,8 & 403,8 & 400,8 \\
\hline Nutrientes Digestíveis Totais & 720,2 & 717,1 & 714,2 & 711,3 & 708,5 \\
\hline Energia Digestível** & 13,4 & 13,4 & 13,4 & 13,3 & 13,2 \\
\hline
\end{tabular}

Fibra em detergente neutro corrigida para cinzas e proteína (FDNcp); Proteína insolúvel em detergente neutro (PIDN); Proteína insolúvel em detergente ácido (PIDA).

* $\mathrm{g} \mathrm{kg}^{-1}$ matéria verde; $* * \mathrm{~kJ} \mathrm{~g}^{-1}$

Fonte: Elaboração dos autores.

O fracionamento dos compostos nitrogenados foi realizado de acordo com o protocolo descrito por Licitra, Hernandez e Van Soest (1996). A Fração "A" ou compostos nitrogenados não proteicos (NNP) foi obtida após o tratamento de $0,5 \mathrm{~g}$ de amostra com $50 \mathrm{~mL}$ de água por 30 minutos, e em seguida realizada a adição de $10 \mathrm{~mL}$ da solução de ácido tricloroacético (TCA) a $10 \mathrm{~mL} \mathrm{~L}^{-1}$, deixandose em repouso por mais 30 minutos. Após este período, filtrou-se em papel de rápida filtragem, e determinou-se o teor de nitrogênio do resíduo mais o papel. A fração A ou NNP foi calculada pela diferença entre o teor de N-total e o N-insolúvel no TCA. A Fração "B3" foi determinada pela diferença 
entre o N insolúvel em detergente neutro (NIDN) e o $\mathrm{N}$ insolúvel em detergente ácido (NIDA). A Fração "C" foi considerada como o NIDA. Obteve-se a fração "B1 + B2" pela diferença entre o $\mathrm{N}$ insolúvel em TCA e o NIDN, ou subtraindo-se de 100 a soma das frações A, B3 e C.

Os parâmetros de cinética de degradação ruminal in vitro das dietas dos diferentes tratamentos foram estimados a partir do método semi-automático da produção cumulativa de gases descrito por Mauricio et al. (1999). O inóculo ruminal foi obtido de bovino adulto fistulado no rúmen e mantido em pastagem, suplementado com um $\mathrm{kg} \mathrm{dia}^{-1}$ de concentrado contendo milho, farelo de soja, uréia e sal mineral. A solução tampão, descrita por Menke e Steingass (1988), foi preparada e aquecida a $39^{\circ} \mathrm{C}$, sob gaseificação contínua com $\mathrm{CO}_{2}$. Cada frasco de incubação recebeu $0,3 \mathrm{~g}$ de amostra, $28,125 \mathrm{~mL}$ de meio de cultura e $3,125 \mathrm{~mL}$ de inóculo ruminal. Para os ajustes de variação, foram incubados frascos considerados branco, contendo as soluções de incubação sem substrato. Os frascos foram hermeticamente fechados utilizando-se rolhas de borracha.

A partir deste momento, a pressão dos gases produzidos pela fermentação do substrato e acumulada nos frascos foi mensurada por meio de um manômetro, nos tempos $1,2,3,4,6,8,10,12$, $14,16,20,24,28,36,48,60,72,84,96,108$ e 120 horas. Os valores de pressão foram convertidos em volume $(\mathrm{mL})$, conforme equação pré-estabelecida para as condições locais: $\hat{\mathrm{Y}}=0,0475+1,9755 \mathrm{P}+$ $0,0141 \mathrm{P}^{2}\left(\mathrm{R}^{2}=0,99\right)$, corrigidos para base seca, e os valores obtidos nos frascos sem substrato (branco) foram descontados.

Para estimativa dos parâmetros de cinética de fermentação ruminal os dados foram aplicados ao modelo logístico bicompartimental proposto por Schofield, Pitt e Pell (1994), descrito a seguir: $\mathrm{V}(\mathrm{t})=\mathrm{VCNF} /\left(1+\exp \left(2-4 * \mathrm{KdCNF}^{*}(\mathrm{~T}-\mathrm{L})\right)\right)+\mathrm{VCF} /$ $(1+\exp (2-4 * \mathrm{KdCF} *(\mathrm{~T}-\mathrm{L})))$, onde: $\mathrm{VCNF}=$ volume máximo de gás da fração dos carboidratos não fibrosos $(\mathrm{mL})$; VCF = volume máximo de gás da fração dos carboidratos fibrosos $(\mathrm{mL}) ; \mathrm{KdCNF}=$ taxa de degradação dos carboidratos não fibrosos ( $\%$ $\left.\mathrm{h}^{-1}\right) ; \mathrm{KdCF}=$ taxa de degradação dos carboidratos fibrosos $\left(\% \mathrm{~h}^{-1}\right) ; \mathrm{T}$ e $\mathrm{L}=$ tempos de incubação (horas) e a latência (horas).

A proporção de metano no gás produzido pela fermentação das dietas foi mensurada nos tempos 12 e 24 horas de incubação. Nesses tempos o gás foi coletado dos frascos de incubação e imediatamente submetido a análise do metano por cromatografia gasosa em equipamento Varian CP-3800 com detector por ionização em chama, contendo uma coluna capilar CPSIL 8 CB de $30 \mathrm{~m}$ de comprimento, $0,25 \mathrm{~mm}$ de diâmetro interno e $0,25 \mu$ diâmetro da fase utilizando os seguintes parâmetros otimizados: temperatura do injetor: $250{ }^{\circ} \mathrm{C}$, vazão do gás de arraste: $1,5 \mathrm{~mL} \mathrm{~min}^{-1}$, programação do forno: $90{ }^{\circ} \mathrm{C}$ $\rightarrow 15^{\circ} \mathrm{C} \mathrm{min}^{-1} \rightarrow 140{ }^{\circ} \mathrm{C} \rightarrow 10^{\circ} \mathrm{C} \mathrm{min}^{-1} \rightarrow 250{ }^{\circ} \mathrm{C}$ (3 min), temperatura do detector: $280{ }^{\circ} \mathrm{C}$, splitless e volume de injeção de $50 \mu \mathrm{L}$. Foi descontado o metano produzido pelos frascos sem substratos (brancos).

$\mathrm{O}$ experimento foi conduzido em delineamento inteiramente casualizado com uma dieta controle e quatro níveis de substituição, e quatro repetições. Os dados foram submetidos à análise de variância e análise de regressão a um nível de significância de 5\%, utilizando o programa estatístico SAS (2003).

\section{Resultados e Discussão}

Os valores da fração solúvel (A), bem como da proteína verdadeira rapidamente degradada somada à fração de degradação intermediária $(\mathrm{B} 1+\mathrm{B} 2)$ da torta de algodão (Tabela 3) estão próximos aos relatados por Pereira et al. (2000) para amostra de farelo de algodão, de 182,8 e 758,4 $\mathrm{g} \mathrm{kg}^{-1}$ de proteína bruta, respectivamente. Verifica-se que as frações proteicas do farelo de soja e da torta de algodão apresentam distinções (Tabela 1). Enquanto a torta de algodão apresenta predominância da fração B1+B2, o farelo de soja tem 207,8 $\mathrm{g} \mathrm{kg}^{-1} \mathrm{MS}$ 
a mais da fração $\mathrm{A}$ em relação à torta de algodão. Assim, a inclusão da torta de algodão reduziu a fração $\mathrm{A}$, e incrementou a fração $\mathrm{B} 1+\mathrm{B} 2$ nas dietas experimentais (Tabela 4). Houve ainda um aumento na fração considerada indigestível (C), a qual corresponde às proteínas associadas à lignina e produtos oriundos da reação de Maillard, altamente resistentes às enzimas microbianas e indigestíveis ao longo do trato gastrintestinal (LICITRA; HERNANDEZ; VAN SOEST, 1996), além de decréscimo na fração proteica associada à parede celular, lentamente degradada no rúmen (B3).

Tabela 3. Frações protéicas dos alimentos constituintes das dietas experimentais.

\begin{tabular}{lcccc}
\hline & Silagem de Sorgo & Milho Moído & Farelo de Soja & Torta de Algodão \\
\hline g kg-1 Matéria Seca $^{-1}$ & & & & \\
Fração A & 108,8 & 1,9 & 274,2 & 66,4 \\
Fração B1 + B2 & 17,7 & 69,1 & 175,2 & 379,4 \\
Fração B3 & 4,3 & 0,3 & 23,6 & 6,3 \\
Fração C & 3,5 & 2,5 & 0,5 & 4,1 \\
\hline kg $^{-1}$ Proteína Bruta & & & & \\
Fração A & 810,2 & 26 & 579 & 145,6 \\
Fração B1 + B2 & 131,6 & 936,9 & 370 & 831,7 \\
Fração B3 & 32 & 3,8 & 49,9 & 13,8 \\
Fração C & 26,1 & 33,2 & 1,1 & 8,9 \\
\hline
\end{tabular}

Compostos nitrogenados não protéicos (Fração A); Proteína verdadeira rapidamente degradada somada à fração de degradação intermediária (Fração B1+B2); Proteína associada à parede celular (Fração B3); Proteína indigestível (Fração C).

Fonte: Elaboração dos autores.

Tabela 4. Frações protéicas das dietas experimentais em função dos níveis de substituição da proteína do farelo de soja pela torta de algodão.

\begin{tabular}{|c|c|c|c|c|c|}
\hline & \multirow{2}{*}{ Controle } & \multicolumn{4}{|c|}{ Nível de substituicão ( $\left.\mathrm{kg} \mathrm{kg}^{-1} \mathrm{~PB}\right)$} \\
\hline & & 0,25 & 0,5 & 0,75 & 1 \\
\hline \multicolumn{6}{|l|}{$g \mathrm{~kg}^{-1} \mathrm{da} M S$} \\
\hline Fração A & 88 & 84,1 & 80,2 & 76,3 & 72,3 \\
\hline Fração B1 + B2 & 46 & 50,1 & 54,3 & 58,5 & 62,7 \\
\hline Fração B3 & 4,5 & 4,2 & 3,9 & 3,5 & 3,2 \\
\hline Fração C & 2,9 & 3 & 3,1 & 3,2 & 3,2 \\
\hline \multicolumn{6}{|l|}{$g \mathrm{~kg}^{-1} \mathrm{da} P B$} \\
\hline Fração A & 546,2 & 538,7 & 530,5 & 522,3 & 514 \\
\hline Fração B1 + B2 & 402,8 & 410,8 & 419,6 & 428,4 & 437,2 \\
\hline Fração B3 & 24,6 & 23,9 & 23,2 & 22,5 & 21,8 \\
\hline Fração C & 26,4 & 26,6 & 26,7 & 26,8 & 27 \\
\hline
\end{tabular}

Compostos nitrogenados não protéicos (Fração A); Proteína verdadeira rapidamente degradada somada à fração de degradação intermediária (Fração B1+B2); Proteína associada à parede celular (Fração B3); Proteína indigestível (Fração C).

Fonte: Elaboração dos autores.

É necessário que haja sincronismo na fermentação de proteínas e carboidratos para uma eficiente síntese microbiana no rúmen e consequente melhoria no desempenho animal (NOCEK; RUSSEL, 1998). 
Apesar de semelhantes quanto ao teor de carboidratos totais na MS, o farelo de soja apresentou $373,3 \mathrm{~g} \mathrm{~kg}$ ${ }^{1}$ CHT's das frações A+B1, composta por açúcares simples com rápida degradação ruminal, amido e pectina, e $623,8 \mathrm{~g} \mathrm{~kg}^{-1} \mathrm{CHT}$ 's da fração B2, que corresponde à fibra potencialmente degradável, além de 2,9 $\mathrm{g} \mathrm{kg}^{-1} \mathrm{CHT}$ 's de fibra indigestível, ou fração C. Já a torta de algodão teve mais de $90 \%$ de seus carboidratos na fração B2 e a fração indigestível foi 473,9\% maior do que a fração A+B1 (Tabela 5). Em consequência, a inclusão da torta de algodão e o aumento dos níveis de substituição reduziram a proporção de açúcares solúveis, e aumentaram as frações de fibra potencialmente degradável e indigestível, sem alterar o teor de carboidratos totais na MS (Tabela 6).

Tabela 5. Frações de carboidratos dos alimentos constituintes das dietas experimentais.

\begin{tabular}{lcccc}
\hline & Silagem de Sorgo & Milho Moído & Farelo de Soja & Torta de Algodão \\
\hline$g$ kg-1 Matéria Seca $^{-1}$ & & & \\
Fração A + B1 & 287,3 & 709,1 & 201,8 & 74,7 \\
Fração B2 & 541 & 173,6 & 261,6 & 434,6 \\
Fração C & 26,4 & 0,2 & 1,3 & 27,2 \\
\hline kg $^{-1}$ CHT’s Totais & & & & \\
Fração A + B1 & 259 & 794 & 373,3 & 11,9 \\
Fração B2 & 708,1 & 205,8 & 623,8 & 931,7 \\
Fração C & 32,9 & 0,2 & 2,9 & 56,4 \\
\hline
\end{tabular}

Carboidratos solúveis (Fração A + B1); Fibra potencialmente degradável (Fração B2); Fibra indigestível (Fração C).

Fonte: Elaboração dos autores.

Tabela 6. Frações de carboidratos das dietas experimentais em função dos níveis de substituição da proteína do farelo de soja pela torta de algodão.

\begin{tabular}{|c|c|c|c|c|c|}
\hline & \multirow{2}{*}{ Controle } & \multicolumn{4}{|c|}{ Nível de substituição $\left(\mathrm{kg} \mathrm{kg}^{-1} \mathrm{~PB}\right)$} \\
\hline & & 0,25 & 0,5 & 0,75 & 1 \\
\hline \multicolumn{6}{|l|}{$g \mathrm{~kg}^{-1} \mathrm{da} M S$} \\
\hline Fração A + B1 & 413,1 & 409,8 & 406,8 & 403,8 & 400,8 \\
\hline Fração B2 & 404,1 & 408 & 411,6 & 415,1 & 418,7 \\
\hline Fração C & 16,2 & 16,8 & 17,3 & 17,8 & 18,3 \\
\hline \multicolumn{6}{|c|}{$\mathrm{g} \mathrm{kg}^{-1}$ dos CHT's Totais } \\
\hline Fração A + B1 & 435,8 & 427,7 & 420,1 & 412,4 & 404,8 \\
\hline Fração B2 & 543,9 & 550,9 & 557,4 & 564 & 570,6 \\
\hline Fração C & 20,3 & 21,4 & 22,5 & 23,6 & 24,7 \\
\hline
\end{tabular}

Carboidratos solúveis (Fração A + B1); Fibra potencialmente degradável (Fração B2); Fibra indigestível (Fração C).

Fonte: Elaboração dos autores.

Alves et al. (2010), estudaram o efeito da substituição do farelo de soja pelo farelo de algodão em dietas com proporção volumoso:concentrado de 60:40, com $145 \mathrm{~g} \mathrm{~kg}^{-1} \mathrm{MS}$ de PB, condições similares às do presente estudo, e relataram diminuição na fração dos carboidratos não fibrosos, variando de
400 a $360 \mathrm{~g} \mathrm{~kg}^{-1}$ MS entre a dieta controle e o maior nível de substituição, bem como pouca alteração nos teores de carboidratos totais, com $783 \mathrm{~g} \mathrm{~kg}^{-1} \mathrm{MS}$ para a dieta controle e $774 \mathrm{~g} \mathrm{~kg}^{-1} \mathrm{MS}$ para o maior nível de substituição, valores também semelhantes aos do presente estudo. 
A substituição do farelo de soja pela torta de algodão não influenciou $(\mathrm{P}>0,05)$ a produção cumulativa de gases provenientes dos CHT's (VCHT) (Figura 1, Tabela 7), evidenciando ausência de efeito entre as dietas sobre sua digestibilidade, que pode ser atribuída ao baixo teor lipídico da torta de algodão utilizada no experimento, próximo ao do farelo de soja (Tabela 1), que não permitiu o incremento no EE das dietas com o aumento nos níveis de substituição (Tabela 2). Silva et al. (2009) e Alves et al. (2010) relataram que não encontraram mudanças na digestibilidade dos carboidratos totais em função da substituição de farelo de soja por farelo de algodão em dietas de vacas leiteiras em produção.

Figura 1. Volume acumulado de produção de gases ( $\mathrm{mL} \mathrm{g}^{-1} \mathrm{MS}$ ) em função do tempo de incubação (horas) de dietas contendo níveis de torta de algodão em sua composição.



Fonte: Elaboração dos autores.

Tabela 7. Estimativa dos parâmetros da cinética de fermentação ruminal in vitro em função do nível de substituição da proteína do farelo de soja pela torta de algodão.

\begin{tabular}{|c|c|c|c|c|c|c|c|c|c|}
\hline & \multicolumn{5}{|c|}{ Nível de substituição $\left(\mathrm{kg} \mathrm{kg}^{-1} \mathrm{~PB}\right)$} & \multirow{2}{*}{$\begin{array}{c}\text { Valor } \\
\mathbf{P}\end{array}$} & \multirow{2}{*}{$\begin{array}{l}\mathrm{CV} \\
(\%)\end{array}$} & \multirow{2}{*}{ Equação de regressão } & \multirow{2}{*}{$\mathbf{R}^{2}$} \\
\hline & Controle & 0,25 & 0,5 & 0,75 & 1 & & & & \\
\hline VCHT & 350,4 & 329 & 352,1 & 353,6 & 352,8 & 0,083 & 3,76 & $\hat{\mathrm{y}}=347,6$ & - \\
\hline VCF & 151,2 & 141,8 & 148,3 & 152,7 & 152,4 & 0,154 & 4,35 & $\hat{y}=149,3$ & - \\
\hline $\mathrm{KdCF}$ & 0,019 & 0,019 & 0,02 & 0,019 & 0,018 & 0,041 & 2,64 & $\begin{array}{c}\hat{y}=0,018782+0,002353 x- \\
0,002943 x^{2} ; \text { Pmax }=0,4 \mathrm{~kg} \mathrm{~kg}^{-1} \text { PB }\end{array}$ & 0,71 \\
\hline $\mathbf{L}$ & 2,52 & 2,84 & 2,78 & 2,58 & 2,43 & 0,799 & 20,66 & $\hat{y}=2,63$ & - \\
\hline VCNF & 194,2 & 182,4 & 198,8 & 195,7 & 195,5 & 0,148 & 4,64 & $\hat{y}=193,3$ & - \\
\hline $\mathrm{KdCNF}$ & 0,07 & 0,074 & 0,073 & 0,068 & 0,068 & 0,096 & 5,03 & $\hat{y}=0,07$ & - \\
\hline
\end{tabular}

Volume final de produção de gases dos carboidratos totais (VCHT), Volume final de produção de gases de carboidratos fibrosos (VCF) e não fibrosos (VCNF) em $\mathrm{mL} \mathrm{g}^{-1}$ de MS; Taxa de degradação dos carboidratos fibrosos (KdCF) e não fibrosos (KdCNF) em $\% \mathrm{~h}^{-1}$; Latência (L) em hora; $\mathrm{CV}=$ coeficientes de variação.

Fonte: Elaboração dos autores. 
O volume final de gases produzido pela degradação dos carboidratos fibrosos (VCF) não foi influenciado pelas dietas $(\mathrm{P}>0,05)$, embora a taxa de degradação dos $\mathrm{CF}(\mathrm{KdCF})$ tenha apresentado efeito significativo $(\mathrm{P}<0,05)$, com comportamento quadrático positivo $\left(\mathrm{R}^{2}=0,71\right)$ (Tabela 7$)$. Assim, é possível inferir que as variações na $\mathrm{KdCF}$, apesar de significativas, não ocorreram em grandeza suficiente para acarretar diferenças na degradação final dos CF em função das dietas após 120 horas de incubação. $\mathrm{O}$ aumento dos carboidratos na fração C foi compensado pelo também aumento da fração B2, não havendo assim redução da disponibilidade de $\mathrm{CF}$ e consequente redução no seu volume final de gases, como explicam Fernandes et al. (2003). Ainda, uma vez que os gases produzidos a partir dos CF originam-se da FDNcp (DETMANN et al., 2009), o incremento que este componente apresentou com o aumento nos níveis de substituição (Tabela 2) não foi suficiente para influenciar o VCF, uma consequência da qualidade da FDNcp, já que a torta de algodão possui $18,4 \mathrm{~g} \mathrm{~kg}^{-1} \mathrm{MS}$ de lignina a mais que o farelo de soja.

A cinética de degradação dos carboidratos não fibrosos (CNF) não foi influenciada pelos níveis de substituição, uma vez que suas taxas de degradação (KdCNF) e volume final de gases (VCNF) não apresentaram efeito significativo entre as dietas experimentais $(\mathrm{P}>0,05)$ (Tabela 7), corroborando com resultados de Silva et al. (2009) e Alves et al. (2010), que não relataram efeitos dos níveis de farelo de algodão em substituição ao farelo de soja sobre a digestibilidade dos CNF em dietas de vacas leiteiras em produção. A ausência de efeito para os parâmetros dos $\mathrm{CNF}$ presume que foram satisfeitos ou mantidos os fatores que afetam o desenvolvimento de microorganismos que utilizam CNF e a degradabilidade deste compartimento no rúmen, tais como a sincronização entre a liberação de energia e nitrogênio (RUSSEL et al., 1992), para todas as dietas.

Detmann et al. (2009) afirmaram que a fração fibrosa está diretamente associada à maior parte dos eventos envolvidos na latência, o que permite atribuir à pouca variação nos teores de lignina e FDNcp entre as dietas (Tabela 2) a ausência de efeito significativo $(\mathrm{P}>0,05)$ dos níveis de substituição sobre esta variável $(\mathrm{L})$.

Quanto à produção de metano entérico (Tabela 8), verificou-se que entre zero e 12 horas de incubação foi produzido em média $27 \%$ do metano total, e os níveis de substituição influenciaram tanto a produção como a proporção de metano $(\mathrm{P}<0,05)$ com efeito quadrático negativo $\left(\mathrm{R}^{2}=0,54\right.$ e 0,56 , respectivamente). Os maiores tempos de incubação, entre 12 e 24 horas, produziram em média $73 \%$ da quantidade total de metano, sem apresentar efeito entre as dietas.

Tabela 8. Produção de metano ( $\left.\mathrm{mL} \mathrm{g}^{-1} \mathrm{MS}\right)$ e proporção de metano $\left(\mathrm{mL} \mathrm{L}^{-1}\right.$ de gás) in vitro das dietas experimentais.

\begin{tabular}{|c|c|c|c|c|c|c|c|c|c|}
\hline \multirow{2}{*}{$\begin{array}{l}\text { Tempo } \\
\text { (h) }\end{array}$} & \multicolumn{5}{|c|}{ Nível de substituição (kg kg-1 PB) } & \multirow{2}{*}{$\begin{array}{c}\text { Valor } \\
\mathbf{P}\end{array}$} & \multirow{2}{*}{$\begin{array}{l}\text { CV } \\
(\%)\end{array}$} & \multirow{2}{*}{ Equação de regressão } & \multirow{2}{*}{$\mathbf{R}^{2}$} \\
\hline & Controle & 0,25 & 0,5 & 0,75 & 1 & & & & \\
\hline \multicolumn{10}{|c|}{$\mathrm{CH}_{4}$ Total $\left(\mathrm{mL} \mathrm{g}^{-1} \mathrm{MS}\right)$} \\
\hline $0-12$ & 14,71 & 6,81 & 9,65 & 12,63 & 13,21 & 0,017 & 25,58 & $\begin{array}{c}\hat{y}=13,283002-18,4219 x+19,5489 x^{2} \\
\text { Pmin }=0,5 k^{2 g ~ k g}{ }^{-1} P B\end{array}$ & 0,54 \\
\hline $12-24$ & 34,19 & 25,21 & 28,42 & 29,08 & 27,48 & 0,6896 & 28,98 & $\hat{y}=29,07$ & - \\
\hline Total & 45,43 & 32,64 & 38,07 & 39,32 & 40,69 & 0,5382 & 24,11 & $\hat{y}=39,58$ & - \\
\hline \multicolumn{10}{|c|}{$\mathrm{CH}_{4}\left(m L \mathrm{~kJ}^{-1} \mathrm{ED}\right)$} \\
\hline Total & 3,38 & 2,44 & 2,85 & 2,96 & 3,07 & 0,5461 & 24,01 & $\hat{y}=2,97$ & - \\
\hline \multicolumn{10}{|c|}{$\mathrm{CH}_{4}\left(m L L^{-1}\right.$ de gás $)$} \\
\hline 12 & 92,79 & 46,02 & 60,91 & 81,42 & 84,39 & 0,0241 & 25,47 & $\begin{array}{c}\hat{y}=84,400146-112,68288 x+120,13 x^{2} \\
P \min =0.5 k^{2} k g ~ g^{-1} P B\end{array}$ & 0,56 \\
\hline 24 & 137,34 & 108,13 & 112,45 & 116,98 & 111,08 & 0,7626 & 28,69 & $\hat{y}=117,68$ & - \\
\hline
\end{tabular}

Fonte: Elaboração dos autores. 
A baixa produção de metano nos tempos iniciais decorre do fato deste período englobar a fase lag (L), ou seja, não há metanogênese até que estejam saturados os locais disponíveis para fixação microbiana e estas sintetizem suas estruturas e enzimas. É possível observar que as maiores médias de produção e proporção de metano entre zero e 12 horas (dieta controle e com $1 \mathrm{~kg} \mathrm{~kg}^{-1} \mathrm{~PB}$ de torta de algodão) coincidem com os menores tempos de colonização requeridos (Tabela 7). Aumento na produção de metano à medida em que aumenta o tempo de incubação também foi observado por Getachew et al. (2005) e Lee et al. (2011) para diversos tipos de dietas, e sugerem que a fração lentamente digestível da dieta (ou seja, fibras estruturais) está associada à maior produção de metano. Estes últimos pesquisadores conduziram incubações até 72 horas e ralataram que a metanogênese é inibida após 24 horas de incubação, sendo em média $81 \%$ da produção de metano verificada até este tempo.

Como resultado da larga metanogênese observada para todas as dietas a partir de 12 horas de incubação, não houve diferença significativa na produção total de metano com base na MS incubada e na quantidade de energia digestível (ED) entre dietas $(\mathrm{P}>0,05)$, ou seja, não ocorreu mitigação ou incremento das emissões de metano por qualquer nível de inclusão da torta de algodão em relação à dieta controle. Confirmam este comportamento Abdalla et al. (2009), que não encontraram efeito da substituição do farelo de soja pelo farelo de algodão nos mesmos níveis deste estudo em dietas com relação volumoso:concentrado 70:30 sobre a produção de metano após 24 horas de incubação in vitro. Kumar et al. (2007), incubando misturas de feno de trigo com tortas oleaginosas na razão 3:1 por 24 horas, relataram não haver diferença na produção de metano entre as dietas com torta de algodão e torta de soja, com médias de 28,19 e 31,14 $\mathrm{mL} \mathrm{g}^{-1} \mathrm{de}$ $\mathrm{MS}$, respectivamente, inferiores às observadas no presente estudo. Considerando-se o poder calorífico do metano $\left(\sim 8.500 \mathrm{kcal} / \mathrm{m}^{3}\right.$ de $\left.\mathrm{CH}_{4}\right)$, o percentual médio da energia digestível (ED) das dietas que foi perdida na forma deste gás totalizou 10,44\%.

Em concordância com os resultados da cinética de degradação ruminal (Tabela 7), foram encontrados resultados em literatura mostrando que a substituição do farelo de soja pela torta ou farelo de algodão não influencia o desempenho de vacas de leite em confinamento (SILVA et al., 2009; ALVES et al., 2010) ou de novilhas de corte em pastejo recebendo suplementação protéica (BARROS et al., 2011). Este fato associado aos resultados de produção de metano entérico (Tabela 8) indica que a carne ou leite provenientes de sistemas de produção animal que utilizem os co-produtos do biodiesel produzido com óleo de soja ou óleo de algodão têm similar desempenho ambiental quanto às emissões de metano entérico. Uma análise comparando o ciclo de vida do biocombustível produzido à partir destas duas oleaginosas poderia indicar o co-produto com menos emissões embutidas.

\section{Conclusões}

A utilização da torta de algodão em substituição à proteína do farelo de soja em dietas para incubação in vitro reduz a proporção de açúcares solúveis, e aumenta as frações de fibra potencialmente degradável e indigestível, sem alterar o teor de carboidratos totais.

O aumento nos níveis de utilização da torta de algodão reduz os compostos nitrogenados não protéicos (Fração A), enquanto incrementa a proteína verdadeira rapidamente degradável somada à fração de degradação intermediária (Fração B1+B2) e a proteína indigestível (Fração C) nas dietas experimentais.

A torta de algodão não interfere na cinética de fermentação ruminal dos carboidratos não fibrosos, e, embora afete as taxas de degradação dos carboidratos fibrosos, o volume de gases oriundo de sua degradação não é alterada.

A substituição do farelo de soja pelo co-produto 
torta de algodão como concentrado protéico em dietas para incubação in vitro não influencia a produção de metano em 24 horas de fermentação.

\section{Referências}

ABDALLA, A. L.; VASCONCELOS, V. R.; GODOY, P. B. de; BUENO, I. C. da S.; PEÇANHA, M. R. S. R.; CAMPOS, F. C. Efeitos de dietas com diferentes níveis de co-produtos da cadeia do biodiesel sobre a fermentação ruminal em ovinos. In: REUNIÃO ANUAL DA SOCIEDADE BRASILIERA DE ZOOTECNIA, 46., 2009, Maringá. Anais... Maringá: Sociedade Brasileira de Zootecnia, 2009. CD-ROM.

ALVES, A. F.; ZERVOUDAKIS, J. T.; ZERVOUDAKIS, L. K. H.; CABRAL, L. S.; LEONEL, F. P.; PAULA, N. F de. Substituição do farelo de soja por farelo de algodão de alta energia em dietas para vacas leiteiras em produção: consumo, digestibilidade dos nutrientes, balanço de nitrogênio e produção leiteira. Revista Brasileira de Zootecnia, Viçosa, MG, v. 39, n. 3, p. 532-540, 2010.

BARROS, L. V.; PAULINO, M. F.; VALADARES FILHO, S. de C.; DETMANN, E.; SILVA, F. G. da; VALENTE, É. E. L.; LOPES, S. A.; MARTINS, L. S. Replacement of soybean meal by cotton seed meal $38 \%$ in multiple supplements for grazing beef heifers. Revista Brasileira de Zootecnia, Viçosa, MG, v. 40, n. 4, p. 852859, 2011.

BHATTA, R.; TAJIMA, K.; TAKUSARI, N.; HIGUCHI, K.; ENISHI, O.; KURIHARA, M. Comparison of sulfur hexafluoride tracer technique, rumen simulation technique and in vitro gas production techniques for methane production from ruminant feeds. International Congress Series, Zurich, v. 1293, p. 58-61, 2006.

BRASIL. Ministério de Minas e Energia. Boletim Mensal de Biodiesel - Setembro de 2011. 2011. Disponível em: $<\mathrm{http} / / / \mathrm{www} \cdot$ anp.gov.br/?dw=58489>. Acesso em: 02 dez. 2011.

DETMANN, E.; SILVA, J. F. C. da; VÁSQUEZ, H. M.; HENRIQUES, L. T.; HADDADE, I. R. Cinética da degradação ruminal dos carboidratos de quatro gramíneas tropicais em diferentes idades de corte e doses de adubação nitrogenada: técnica de produção de gases. Revista Brasileira de Zootecnia, Viçosa, MG, v. 38, n. 1, p. 149-158, 2009.

FERNANDES, A. M.; QUEIROZ, A. C.; PEREIRA, J. C.; LANA, R. P.; BARBOSA, M. H. P.; FONSECA, D. M. da; DETMANN, E.; CABRAL, L. S.; PEREIRA, E. S.; VITTORI, A. Composição químico-bromatológica de variedades de cana-de-açúcar (Saccharumspp L.) com diferentes ciclos de produção (precoce e intermediário) em três idades de corte. Revista Brasileira de Zootecnia, Viçosa, MG, v. 31, n. 4, p. 977-985, 2003.

GETACHEW, G.; ROBINSON, P. H.; DEPETERS, E. J.; TAYLOR, S. J.; GISI, D. D.; HIGGINBOTHAM, G. E.; RIORDAN, T. J. Methane production from commercial dairy rations estimated using an in vitro gas technique. Animal Feed Science and Technology, Davis, v. 123-124, n. 1, p. 391-403, 2005.

HOPKINS, A.; DEL PRADO, A. Implications of climate change for grasslands in Europe, impacts, adaptations and mitigation options: a review. Grass and Forage Science, Canberra, v. 62, n. 2, p. 118-126, 2007.

KEBREAB, E.; STRATHE, A.; FADEL, J.; MORAES, L.; FRANCE, J. Impact of dietary manipulation on nutrient flows and greenhouse gas emissions in cattle. Revista Brasileira de Zootecnia, Viçosa, MG, v. 39, p. 458-464, 2010. Suplemento Especial.

KUMAR, R.; KAMRA, D. N.; AGARWAL, N.; CHAUDHARY, L. C. In vitro Methanogenesis and fermentation of feeds containing oil seed cakes with rumen liquor of buffalo. Asian-Australian Journal of Animal Sciences, Seoul, v. 20, n. 8, p. 1196-1200, 2007.

LASCANO, C. E.; CARDENAS, E. Alternatives for methane emission mitigation in livestock systems. Revista Brasileira de Zootecnia, Viçosa, MG, v. 39, p. 175-182, 2010. Suplemento Especial.

LEE, SE-Y.; LEE, SANG-M.; CHOA, YOUNG-B.; KAM, DONG-K.; LEE, SANG-C.; KIM, CHANG-H.; SEO, S. Glycerol as a feed supplement for ruminants: In vitro fermentation characteristics and methane production. Animal Feed Science and Technology, Davis, v. 166-167, n. 23, p. 269-274, 2011.

LICITRA, G.; HERNANDEZ, T. M.; VAN SOEST, P. J. Standardization of procedures for nitrogen fractionation of ruminant feeds. Animal Feed Science and Technology, Davis, v. 57, n. 4, p. 347-358, 1996.

MAURICIO, R. M.; MOULD, F. L.; DHANOA, M. S.; OWEN, E.; CHANNA, K. S.; THEODOROU, M. K. A semi-automated in vitro gas production technique for ruminants feedstuff evaluation. Animal Feed Science and Technology, Davis, v. 79, n. 4, p. 321-330, 1999.

MENKE, K. H.; STEINGASS, H. Estimation of the energetic feed value obtained from chemical analysis and gas production using rumen fluid. Animal Research and Development, v. 28, p. 7-55, 1988.

MIZUBUTI, I. Y.; PINTO, A. P.; RAMOS, B. M. O.; PEREIRA, E. S. Métodos laboratoriais de avaliaçãode alimentos para animais. Londrina: EDUEL, 2009. 228 p. 
NATIONAL RESEARCH COUNCIL - NRC. Nutrient requirements of dairy cattle. $7^{\text {th }}$ ed Washington. DC: National Academy Press, 2001. 381 p.

NOCEK, J.; RUSSEL, J. B. Protein and carbohydrate as an integrating system. Relationship of ruminal availability to microbial contribution and milk production. Journal of Dairy Science, Champaign, v. 71, n. 5, p. 2070-2075, 1998.

PEREIRA, E. S.; QUEIROZ, C. A.; PAULINO, M. F.; CECON, P. R.; VALADARES FILHO, S. C.; MIRANDA, L. F.; FERNANDES, A. M.; CABRAL, L. S. Determinação das frações protéicas e de carboidratos e taxas de degradação in vitro da cana-de-açúcar, da cama de frango e do farelo de algodão. Revista Brasileira de Zootecnia, Viçosa, MG, v. 29, n. 6, p. 1887-1893, 2000.

RAMASWANY, V.; BOUCHER, O.; HAIGH, J.; HAUGLUSTAINE, D.; HAYWOOD, D.; MYHRE, G.; NAKAJIMA, T.; SHI, G. Y.; SOLOMON, S. Radiative forcing of climate change. In: HOUGHTON, J.T.; DING, Y.; GRIGGS, D.J.; NOGUER, M.; VAN DER LINDEN, P.J.; DAI, X.; MASKELL, K.; JOHNSON, C.A. (Ed.). Climate change 2001: the scientific basis. Contribution of working group I to the third assessment report of the intergovernmental panel on climate change. Cambridge: Cambridge University Press, 2001. cap. 6, p. 349-416.

RUSSEL, J. B.; O’CONNOR, J. D.; FOX, D. G.; VAN SOEST, P. J.; SNIFFEN, C. J. A net carbohydrate and protein system for evaluating cattle diets: I. Ruminal fermentation. Journal of Animal Science, Champaign, v.
70, n. 11, p. 3551-3561, 1992.

SAS INSTITUTE. SAS user's guide: statistics; version 9.1.3. Cary, 2003. 965 p.

SCHOFIELD, P.; PITT, R. E.; PELL, A. N. Kinetic of fiber digestion from in vitro gas production. Journal of Animal Science, Champaign, v. 72, n. 11, p. 2980-2991, 1994.

SILVA, F. M. da; FERREIRA, M. de A.; GUIM, A.; PESSOA, R. A. S.; GOMES, L. H. dos S.; OLIVEIRA, J.C.V. de. Replacement of soybean meal by cottonseed meal in diets based on spineless cactus for lactating cows. Revista Brasileira de Zootecnia, Viçosa, MG,v. 38, n. 10, p. 1995-2000, 2009.

SNIFFEN, C. J.; O’CONNOR, J. D.; VAN SOEST, P. J.; FOX, D. G.; RUSSEL, J. B. A net carbohydrate and protein system for evaluating cattle diets. II Carbohydrate and protein availability. Journal of Animal Science, Champaign, v. 70, n. 11, p. 3562-3577, 1992.

SOLOMON, S.; QIN, D.; MANNING, M.; CHEN, Z.; MARQUIS, M.; AVERYT, K. B.; TIGNOR, M.; MILLER, H. L. Report of the intergovernmental panel on climate change. Cambridge: Cambridge University Press, 2007.

WHEELER, D. M.; LEDGARD, S. F.; DE KLEIN, C. A. Using the overseer nutrient budget model to estimate on-farm greenhouse gas emissions. Australian Journal of Experimental Agriculture, Collingwood, Australia, v. 48, n. 2, p. 99-103, 2008. 